\title{
Consultant-liaison psychiatrists and euthanasia in The Netherlands
}

\author{
Frits J. Huyse, Willem van Tilburg, Ine Klijn and Gertie Casteelen
}

\section{Extent and legal aspects}

On 30 November 1993 a nine year political debate on euthanasia closed; the first chamber of the Dutch parliament ratified the law on undertaking, including euthanasia regulations. This political step concluded, for the time being at least, a legal, public, political and medical debate, which started in 1973, when a medical doctor was convicted for performing euthanasia on her mother. In a first effort in 1983, parliament falled to legalise euthanasia. In 1989 a new government introduced an initiative to improve the existing law in this regard. As a part of the process, empirical data on the extent of euthanasia in The Netherlands were required. Therefore, the Minister of Justice installed a committee. Its findings have been reported nationally and internationally (van der Maas et al, 1991a, 1991b); about 2,300 euthanasia cases in 1990 , being $1.8 \%$ of all deaths. These empirical findings reduced the uncertainties about the extent of euthanasia, thereby providing a sound basis for the parliamentary decision-making process. Although by the current law euthanasia and assisted suicide still remain illegal, under strict guidelines for behavlour provided by the Ministry of Justice in November 1990 and distributed among physicians in January 1991, euthanasia can be exempted by the public prosecutor from criminal punishment on the basis of the 'opportunity' principle, this being the opportunity for the public prosecutor not to bring all reported crimes to court (Letter of the Minister of Justice to Parliament, 1990).

\section{Current practice guidelines for euthanasia}

The 1991 practice guidelines are divided into four parts: the patient's history, the independence and freedom of the patient's request for euthanasia, the consultation of another independent doctor, and the way euthanasia has been performed. First, the patient's history should include a detalled description of the course of the physical illness, but the major emphasis is on assessment of the unbearable and dehumanising aspects of the physical and psychological condition. Second, to assess the freedom and independence of the request, the emphasis is placed on its clarity, on its perseverance based on appropriate information provided by the doctor, and on the patient's full awareness of its implications. This section in particular refers to the possibility of psychiatric disturbances interfering with the decision-making process. Third, the doctor is asked whether or not another independent colleague - that is, someone who is not involved in the treatment of the patient - has seen the patient and carefully reviewed the above mentioned issues, and whether this colleague came to the same conclusion. Fourth, the whole procedure, including the above mentioned sections (25 questions), has to be documented in a report of unnatural death which is forwarded to the coroner. In case of doubt the prosecutor is informed, which may result in the family and doctor being heard, and an autopsy performed. Under the 1993 law, the need for an active evaluation of reported euthanasia cases by the prosecutors is stressed.

\section{Who is involved?}

As is apparent from the available figures, euthanasia is primarily an issue in family practice $(1,500$ of the 2,300$)$, carried out by general practitioners (GPs), who play a pivotal role in the health care process (Van der Maas, 1991; Huyse et al, 1989). The second commonest site is the general hospital, whereas in nursing homes non-treatment decisions were more prevalent and euthanasia seemed less of an issue (Van der Maas, 1991). Therefore, doctors involved are GPs, internists/oncologists, pulmonologists, neurologists, and, if at all, nursing home physicians. As far as the involvement of another independent doctor is concerned, an investigation assessing euthanasia in primary care practice in 1990 (prior to the practice guidelines) revealed other colleagues being consulted in $75 \%$ of cases (Van der Wal et al, 1992a, 1992b). When consultation was asked for, $60 \%$ of the requests were addressed to another GP often part of the 
practice substitute group, and in $28 \%$ a medical specialist, the latter being most often actively involved in the treatment of the patient. In only $5 \%$ of cases an independent consultation was asked for from a doctor who was not familiar with the patient beforehand. These findings led to the conclusion that GPs did not always consult another doctor. Although it was apparent from a review of the figures from 1985 to 1990 that the number of consultations increased when GPs consulted another doctor, it was most often not an independent doctor, and psychiatrists play a minor role as they are not mentioned as a medical discipline that might be involved.

In September 1993 a survey was circulated among consultant-liaison (C-L) psychiatrists who were members of The Netherlands Consortium for Consultation-liaison Psychiatry (NCCP), a group comparable with the Royal College Liaison Group, to assess the extent and the quality of their participation in and their opinion on their role in euthanasia (Huyse et al, 1993). The NCCP members represent about $40 \%$ of the general hospitals in The Netherlands. The response rate was $65 \%$. As far as the characteristics of the respondents' hospitals are concerned, they can be regarded as fairly representative of Dutch general hospitals. From the 32 responding $\mathrm{C}-\mathrm{L}$ psychiatric services, four services had never been involved. When asked for a hierarchy of reasons for consultation, in all cases the assessment of judgement was a reason; additional reasons included being asked as the 'independent doctor' (57\%), and to support difficult treatment decisions (75\%). Twenty-one of the 32 hospitals had nominated independent consultants to assess the implementation of the practice guidelines, but none of these consultants was psychiatrists. These practice guidelines in general hospitals anticipated the guidelines provided by the minister of justice, including assessment by an independent doctor.

\section{Position of C-L psychiatrists in The Netherlands}

The systematic development of C-L psychiatry started in the beginning of the 80 s (Huyse et al, 1989). During the last five years there has been a growing communication between C-L psychiatrists throughout Europe (Huyse et al, 1991; Mayou et al, 1991). This is especially true for communication between UK and Dutch C-L psychiatrists. The close working relationships developed through the ECLW Collaborative Study have highlighted differences in development and the organisation of $\mathrm{C}-\mathrm{L}$ in The Netherlands compared with the UK (Huyse et al, 1991; Mayou et al, 1991). In The Netherlands $55 \%$ of general hospitals have psychiatric wards.
Other hospitals have only out-patient facilities (20\%). In the other $25 \%$ only C-L services are available. Consequently there is a considerable group of psychiatrists who work full, or part time in $\mathrm{C}-\mathrm{L}$, in the general hospital setting. Finally, all eight university hospitals have active C-L services taking part in the teaching of the psychiatric curriculum (Institute of Mental Health, 1994).

\section{Role of C-L psychiatrists in euthanasia}

During recent years there has been a series of discussions between members related to this subject. The first complex euthanasia case was presented during one of the three annual NCCP meetings. The case was an example of strong emotional involvement by ward staff who were willing to support a euthanasia request. A psychiatrist was consulted; in his opinion it was quite questionable whether the patient was terminal; moreover the patient had impaired judgement due to a depressive illness and there was an inappropriate approach towards the patient due to the emotional involvement. The consultant expressed his opinion that there was no indication for euthanasia and made specific treatment recommendations. Yet, the consultee rejected this advice and did not abstain from euthanasia. The discussion focused on the interaction between consultant and consultee and on the legal aspects of the involvement of the psychiatrist.

In Spring 1993 a meeting was dedicated to assess the possibility of gradual development of practice guidelines for $C-L$ psychiatrists on the basis of a series of case presentations. During these discussions it became apparent that requests for psychiatric involvement in the assessment of patients asking for euthanasia posed many difficulties as psychiatrists were expected to fulfil different roles. First, the psychiatrist can be asked to confirm a clear case of euthanasia. This is a rare request. Second, the psychiatrist can be asked to specifically assess the mental state of the patient to outrule any suspicion of impaired judgement. As discussed earlier, impaired judgement alone is not a reason to abstain from euthanasia (Huyse et al, 1993). Such an interpretation is a specific task for a C-L psychiatrist. Third, a psychiatrist can be asked to evaluate patient staff conflict, when the patient is in favour of euthanasia and the staff doubt its appropriateness.

It is evident from current practice that $\mathrm{C}-\mathrm{L}$ psychiatrists do not have a key role in the euthanasia decision process in the out-patient or inpatient general health care sector. The results of the NCCP survey reveal a harmony between this 
current practice and the aspirations of C-L psychiatrists. C-L psychiatrists see themselves as consultants in cases of suspected mental health problems, or in cases of team conflict. Although C-L psychiatrists could have opted for a key position, it is probably wiser to have opted for this limited role. The results of the existing surveys and studies, the guidelines presented by the Secretary of Justice, the guidelines suggested by the Dutch Right to Die Society, and by the Dutch Royal College of Physicians do not provide a sound political basis for more active participation by $\mathrm{C}-\mathrm{L}$ psychiatrists in decisions on euthanasia in the general hospital sector.

Since the 60 s, Dutch psychiatrists have abstained themselves from the core of the medical practice by increasing the split between general health care and mental health care, deleting obligatory neurological training and by focusing on psychotherapy. Although there is currently an increasing emphasis on general hospital psychiatry, this does not seem the right time to opt for a mandatory participation. At the moment psychiatrists should be readily available for difficult treatment decisions in the general hospital setting. General hospital psychiatry's emphasis on the interface between psychiatry and medicine will place the $C-L$ psychiatrist in a position to become a more active participant in medical decision-making, including decisions concerning the end of life. Yet, it is quite evident that the more active audit of euthanasia cases by the prosecutor under the current law, the growing experience of $\mathrm{C}-\mathrm{L}$ psychiatrists with this phenomenon and the more open discussion of current practice could result in argument for a more active or even standardised role of psychiatrists in euthanasia requests.

\section{Euthanasia in the mentally ill}

This article has its focus on the issue of euthanasia in the medically ill. It does not involve the current revived discussion among psychiatric professionals on physician-assisted suicide in unbearable mental illness, such as patients suffering from treatment refractory psychiatric illness with continuous suicidal ideation, and the elderly, including seriously demented patients, having living wills and/or families in support of euthanasia (Royal Dutch Medical Association, 1993; Legemaate, 1993). The Netherlands Psychiatric Association (1992) has taken its position in the discussion on physician assisted suicide in psychiatric patients. It focuses on three main issues:

(a) the fact that the presence of psychiatric illness does not impair judgement per se, meaning that in cases with psychiatric illness euthanasia or physician assisted suicide could be considered

(b) The fact that psychiatric illness can be as unbearable and as treatment resistant as physical disease, meaning that a split between psychiatric and physical illness is unjustified and should be avoided as it discriminates against the mentally ill, and therefore

(c) the conditions for physician-assisted suicide or euthanasia should be basically the same as in the physically ill, that is, chronic and unbearable suffering, a consistent and persistent request, no treatment options taking the state of the art into account, and the wish should be autonomous and independent.

It is evident that seriously demented patients. where judgement is impaired and treatment options are limited, pose a specific problem. A committee of the Royal Dutch Medical Association (1993) focusing on this issue did not provide practice guidelines, yet they have carefully described the lines along which thinking on this issue could develop. It should be perfectly clear that although frequently talked about, physician-assisted suicide in such cases is a rare event; the estimate of experts is less than ten cases a year.

\section{References}

LEGEMATE, J. (1993) Hulp bij zelfdoding in de psychiatrie: regels en opvattingen. Maandblad Geestelike Volks gezondhetd, 7/8, 750-770.

HuYSE, F.J. \& HENGEVELD, M.W. (1989) The development of C/L psychiatry in The Netherlands: its social psychiatric heritage. General Hospital Psychiatry, 11, 9-15.

- AND MEMBERS OF THE ECLW (1991) Consultation-liaison psychiatry: Does it help to get organized? General Hospital Psychiatry. 13, 183-187.

- \& van TILBURG, W. (1993) Euthanasia policy in The Netherlands: the role of consultation-liaison psychiatrists. Hospital and Community Psychiatry. 44, 733-738.

MAAS VAN DER. P.J., DELDEN VAN, J.J.M., PINENBORG, L. \& LOOMAM, C.W.N. (1991a) Euthanasia and other medical decisions concerning the end of life. The Lancet, 338, $669-674$.

-, -, -. (1991b) Medische beslissingen rond het lev enseinde. Het onderzoek voor de Commissle Onderzoek Medische Praktijk Inzake Euthanasie. SDU Uitgeverij The Hague.

MAYOU, R., HUYSE, F.J. AND THE ECLW (1991) ConsultationLiaison Psychiatry in Western Europe. General Hospital Psychiatry. 13, 188-208.

MINISTER OF JUSTICE (1990) Letter of the Minister of Justice to parliament. Tweede Kamer, vergaderjaar 1990-1991. 21800 VI. $\mathrm{nr}$ 23. 015474F ISSN 0921-7371. SDU Uitgeverij The Hague.

NEDERLANDSE VERENIGING VOOR VRLJWILLIGE EUTHANASIE (RIGHT TO DIE SOCIETY): Proposal for a Euthanasia protocol. Nederlandse Vereniging voor Vrijwillige Euthanasie PO Box 75331, 1070AH Amsterdam.

Netherlands INSTTtUTE of MENTAl Health (1994) Menta Health Services in the General Hospital: internal report. 
NETHERLANDS PSYChIATRIC ASSOCLATION (1992) Mededelingen bestuur. Nieuws en mededelingen, 86, 2-3.

ROYal DUTCH MEdical Association Utrecht (1993) Medical Decisions Concerning the End of Life: Part III. Serious demented patients. Working paper.

WAL, G. VAN DER, ELK, J.TH.M. VAN, LEENEN, H.J.J. \& SPREEUWENBERG, C. (1992a) Euthanasia and assisted suicide. I. How often is it practiced by family doctors in The Netherlands? Family Practice, 9, 130-134.

,,,.---- (1992b) Euthanasia and assisted suicide. II. Do Dutch family doctors act prudently? Family Practice. 9. 135-140.

*Frits J. Huyse, Director, C-L Psychiatric Service, Associate Professor in Psychiatry. Free University
Hospital, Amsterdam, The Netherlands; Willem van Tilburg. Chairman, Department of Psychiatry. Free University of Amsterdam, Amsterdam The Netherlands; Ine Klijn, C-L Psychiatric Service, University Hospital Utrecht, Utrecht, The Netherlands; and Gertie Casteelen, C-L Psychiatric Service, University Hospital Amsterdam, Amsterdam. The Netherlands

*Correspondence: Department of C-L Psychiatry. Free University Hospital. De Boelelaan 1117. PO 7075 Box 1071 MB Amsterdam. The Netherlands

\title{
A view from the road: experiences in four continents
}

\author{
Vikram Patel
}

Since graduating from medical school eight years ago, I have had the chance of experiencing clinical psychiatry in four countries on four continents; Bombay and Goa, India, my home, where $I$ trained in medicine and began my psychiatric training; Oxford and London, United Kingdom, where I acquired a taste for academic psychiatry and completed my clinical training; Sydney, Australia, where I worked in a liaison unit in a large general hospital and a community mental health centre; and now, Harare. Zimbabwe, where I am conducting a two year study on traditional concepts of mental illness and the role of traditional healers and other care providers in primary mental health care.

Travelling to new cultures as a tourist is in itself an enriching experience; travelling to work is altogether different. The quick explorations of tourist spots take a back seat to the essential tasks of 'living': overcoming complex immigration and medical licensing bureaucracies, settling in to a new work environment, working with new languages, developing a social structure and so on. Amidst all this are the exhilarating opportunities of learning about the cultures with a level of intimacy that psychiatry allows more than many professions. Most of all, though, is the experience of life in a new setting, at a different pace, with new colours, smells, climates, food, music, social system and more. In this article, I will attempt to share some of the difficulties and joys of my cross-cultural experiences in the hope that some of my colleagues may be inspired to pack their bags in anticipation!

\section{Where does one go and how does one get a job?}

The world may be shrinking for most people, but for medical professionals there is a different perspective. In the past two decades, many countries have erected barriers to the free flow of medical personnel across national boundaries (Patel \& Araya, 1992). Indian medical degrees were fully acceptable in the UK just ten years ago but we are now expected to 'requalify' by sitting exams. Now, even British degrees are not accepted in India, Australia or the USA. And as the tit-for-tat continues, often instigated by the bodies that represent the needs of doctors themselves, the barriers get higher. There is a need for the medical councils of different nations to establish a dialogue on how to improve the cross-national acceptability of one another's qualifications. After all, the system of medicine as practised in all four countries I have worked in is virtually indistinguishable. There still are a few routes open (other than resitting general medical exams, which after several years in psychiatry can be a demoralising life event); some countries 